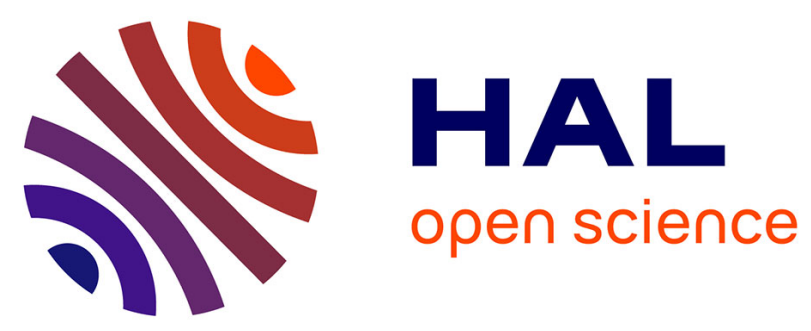

\title{
'What is it like to have ME?': The discursive construction of ME in computer-mediated communication and face-to-face interaction
}

Jennifer Guise, Sue Widdicombe, Andy Mckinlay

\section{> To cite this version:}

Jennifer Guise, Sue Widdicombe, Andy Mckinlay. 'What is it like to have ME?': The discursive construction of ME in computer-mediated communication and face-to-face interaction. Health:, 2007, 11 (1), pp.87-108. 10.1177/1363459307070806 . hal-00571433

\section{HAL Id: hal-00571433 \\ https://hal.science/hal-00571433}

Submitted on 1 Mar 2011

HAL is a multi-disciplinary open access archive for the deposit and dissemination of scientific research documents, whether they are published or not. The documents may come from teaching and research institutions in France or abroad, or from public or private research centers.
L'archive ouverte pluridisciplinaire HAL, est destinée au dépôt et à la diffusion de documents scientifiques de niveau recherche, publiés ou non, émanant des établissements d'enseignement et de recherche français ou étrangers, des laboratoires publics ou privés. 


\title{
'What is it like to have \\ ME?': The discursive \\ construction of $\mathrm{ME}$ in \\ computer-mediated \\ communication and face- to-face interaction
}

Vol 11(1): 87-108

\author{
Jennifer Guise, Sue Widdicombe and Andy McKinlay \\ University of Abertay, Dundee, UK, University of Edinburgh, UK and \\ University of Edinburgh, UK
}

\begin{abstract}
A B S T R A C T ME (Myalgic Encephalomyelitis) or CFS (chronic fatigue syndrome) is a debilitating illness for which no cause or medical tests have been identified. Debates over its nature have generated interest from qualitative researchers. However, participants are difficult to recruit because of the nature of their condition. Therefore, this study explores the utility of the internet as a means of eliciting accounts. We analyse data from focus groups and the internet in order to ascertain the extent to which previous research findings apply to the internet domain. Interviews were conducted among 49 members of internet groups ( 38 chatline, 11 personal) and 7 members of two face-to-face support groups. Discourse analysis of descriptions and accounts of ME or CFS revealed similar devices and interactional concerns in both internet and faceto-face communication. Participants constructed their condition as serious, enigmatic and not psychological. These functioned to deflect problematic assumptions about ME or CFS and to manage their accountability for the illness and its effects.
\end{abstract}

K EYWORDS computer-mediated communication (CMC); discursive psychology; illness descriptions; $M E / C F S$

A D D R E S S Jennifer Guise, Tayside Institute for Health Studies, University of Abertay, Dundee, Dudhope Castle, Barrack Road, Dundee DD3 6HF, UK. [E-mail: J.Guise@abertay.ac.uk]

\section{Introduction}

ME (Myalgic Encephalomyelitis) is the preferred term among UK sufferers for a condition clinically referred to as chronic fatigue syndrome (CFS). This 
illness affects between 110,000 and 150,000 people per annum in the UK (Cooper, 1997; Levine, 1997). It is often highly debilitating and yet it remains a controversial and problematic illness for both clinicians and patients. This is in part because, despite extensive investigation, no clear cause has been established (Fukuda et al., 1994; Wessely et al., 1998), and no unambiguous diagnostic medical tests identified. Instead, ME or CFS is diagnosed on the basis of reported symptoms, and these can vary in nature and in intensity from one person to another. They may include reports of persisting or relapsing fatigue lasting six months or more; sore throat; tender lymph nodes; joint and muscle pain; headaches; post-exertion malaise; sleep disorder; and impaired memory or concentration (Fukuda et al., 1994; Holmes et al., 1988; Schluederberg et al., 1992; Sharpe et al., 1991).

Due to the uncertainty surrounding the causes and 'objective' diagnosis of ME or CFS, there have been debates over the extent to which psychological or psychiatric problems contribute to this condition (for example, in official statements about this illness: Campion, 1998; Horton, 1996; Royal College of Physicians, 1996). At the same time, the medical account of the illness has been challenged by patient organizations such as the ME/CFS Alliance (Banks and Prior, 2001) in favour of their own experience-based explanations (for brief summaries of these controversies, see HortonSalway, 2001; Tucker, 2004).

The contested nature of ME/CFS has also generated interest from qualitative researchers interested in the effects of this uncertainty. Three issues in particular have been pursued:

1. Variability in the meaning and construction of ME/CFS;

2. warranting knowledge claims about ME/CFS; and

3. dealing with the implication that sufferers may have a psychological rather than physical illness.

In relation to the first issue, Bülow and Hydén (2003) identified at least three 'interpretative frameworks' that were used often simultaneously by patients, nurses and physicians in the patient school they studied. These included biomedical, biopsychosocial and non-medical or everyday explanations of the illness. Banks and Prior (2001) noted the use of similar accounts of the illness in their study of medical consultations. Their concern, however, was more specifically with the conflict between lay (biomedical) versus professional (biopsychosocial) accounts. They argued that consultations can become almost a political contest as different parties seek to define the 'true' nature of the disorder.

Horton-Salway (2004), however, questioned the implied distinction between lay and expert knowledge because it rests on the assumption that there are discrete and identifiable forms of knowledge. She argued that 'it should be the local production of expertise and experience and the legitimacy of related claims that is the focus of interest' (2004: 354). Thus, HortonSalway's (2004) analysis focused on the second issue, that is, how a clinical psychologist and sufferers establish their entitlement to make authoritative 
claims about ME. She showed that they do so in part by making relevant their membership of particular categories (as, respectively, expert in psychological intervention and sufferers with a wealth of experience). She showed how expertise and experience were treated as forms of knowledge that added credibility to a speaker's account or undermined others' accounts. Similarly Tucker (2004) examined how sufferers constructed ME/CFS as a knowable, legitimate illness by drawing a contrast between a specialist doctor who can produce a correct diagnosis and 'ordinary' GPs who lack knowledge of and therefore the ability to recognize ME or CFS in sufferers.

Other work has examined how participants employ conversational strategies such as the use of medical terms and corroborative evidence (Horton-Salway, 2001; Tucker, 2004) to establish the factual status of their claims that ME/CFS is a physical and therefore legitimate illness. In addition, Bülow and Hydén (Bülow, 2004; Bülow and Hydén, 2003) show how sufferers deal with the problem of legitimacy by co-constructing consensual views (for example, in support groups) against which personal experience is compared. In this way, the group experience is used to validate individuals' experiences.

A third issue concerns the inferential consequences of the questioned legitimacy of ME/CFS, in particular, the idea that it is primarily psychological (that is, related to depression, anxiety and psychiatric illness) (Banks and Prior, 2001; Horton-Salway, 2004) and therefore not real (Banks and Prior, 2001). For example, it may be inferred that sufferers are simply malingering (Horton-Salway, 2001) or they may be stigmatized because it is more socially acceptable to suffer physical illness (Tucker, 2004). All of these assumptions have negative implications for the kind of person one is taken to be, and they therefore constitute a threat to identity. The third strand of work has therefore focused on how sufferers deal with these problematic inferences. Some of these identity problems are dealt with through establishing the legitimacy and veracity of ME/CFS (as above). However, sufferers may also produce attributions for the onset of the illness (for example, catching 'flu), which simultaneously attend to their accountability for having it (Tucker, 2004; see also Horton-Salway, 2001). They also address negative identities directly, for example by constructing themselves as previously very active, thereby deflecting the possible inference that they are lazy or depressed (Horton-Salway, 2001). Finally, Banks and Prior show how physicians may be sensitive to these problems and deal with them by 'by-pass[ing] psychological language' (2001:20) and using instead the vocabulary of brain chemicals (such as serotonin) which in turn opens the possibility of prescribing anti-depressants without talk of depression.

Previous studies have revealed some of the ways in which the talk of clinicians and sufferers is sensitive to a number of interactional and inferential issues. The data have been derived from face-to-face interaction in interviews (Bülow, 2004; Bülow and Hydén, 2003; Horton-Salway, 2001; Tucker, 2004) 
and recordings of meetings among members of a support group (HortonSalway, 2004) or patient school (Bülow, 2004; Bülow and Hydén, 2003). However, none of the previous studies in this area have attended to the way in which the internet provides a domain for interactions and support among sufferers. Yet, internet communication offers a valuable resource for ME sufferers, as for others who are chronically ill (Hardy, 1999) or who have incapacitating physical or speech difficulties (Bowker and Tuffin, 2004). It is therefore imperative that researchers engage with these new forms of communication especially in regard to this client group. Moreover, recent years have seen a growth in internet mediated support groups and there is evidence that the use of the internet for purposes of this sort is likely to increase (Nettleton and Burrows, 2003).

This study therefore recruited participants from an internet support site. There are, moreover, further benefits to be derived from the use of the internet as a medium for conducting research in this area. First, it is worthwhile noting that a number of previous studies of this sufferer group have engaged with relatively small participant samples. An added advantage of attending to the rise of internet-based communication is that researchers in this area are given greater opportunities to recruit from a wider range of participants. Second, it has the advantage of enabling participants to respond where and when they feel most comfortable and rested, and to break off and resume the interview as necessary. Similar advantages have been described for telephone interviewing (Clarke and James, 2003).

Thus, it seems that the internet is a useful medium for research but we first need to ask how it relates to the kind of talk generated in face-to-face communication that has formed the data for previous research. In other words, we need to address the extent to which findings from previous research carry over into the internet domain and computer-mediated communication (CMC). In particular, previous researchers' interests have been in understanding the attributional and inferential properties of talk about ME. It is therefore crucial to understand the extent to which their findings, which relate to face-to-face interaction, are relevant to sufferers' 'talk' on the internet. It is to this novel enterprise that this current article is addressed.

In addressing these concerns, it is useful to note that researchers in other areas have already demonstrated the ways in which CMC reflects properties which are similar to spoken communication. Yates (2001) found that the range of vocabulary used in CMC resembled oral vocabulary rather than written communication in terms of the more limited variance in words used. Fernback (2003) also concluded that CMC is a site of oral culture, although one that undoubtedly possesses print characteristics. Other work has addressed the functional properties of CMC language use. For example, Antaki et al., (2005) and Lamerichs and te Molder (2003) show how internet users, like participants in conversation, attend to issues of accountability in postings. These studies call into question the assumption of earlier research, 
that CMC is an impoverished or somehow different form of communication (for example Rutter, 1984; Short et al., 1976). Therefore, we cannot assume a priori that CMC changes human interaction in specific ways, or that the influence is only in one direction; instead, this must be an empirical issue (Hutchby, 2001a, 2001b). It is therefore important that we collect data from both face-to-face and internet sources.

\section{The present study}

In this study, sufferers' accounts of having ME/CFS were collected through internet and face-to-face discussion groups. Our aim was to examine in detail how sufferers' descriptions are constructed and, if relevant, to identify the kinds of interactional and inferential issues that inform their production. The focus, on participants' constructions of ME, was designed to ensure that our findings would be comparable to those of previous studies.

Like previous studies, we assume that descriptions are not neutral accounts of some aspect of the way the world is which can be assessed for their accuracy. After all, phenomena may be described in many different but equally plausible ways. We therefore take it that people can and do use descriptions to perform actions (Potter, 1996), and that the actionorientation of descriptions is achieved through the ways they are constructed (e.g. through the use of particular words or phrases). Moreover, they are usually produced in an interpersonal context and, given this, there is always the possibility that descriptions may be greeted with scepticism (Hutchby and Wooffitt, 1998). For example, they may be treated as a product of the person's own interests, desires or ambitions, and discounted on this basis as interested rather than neutral (Edwards and Potter, 1992). Descriptions are therefore often designed to deal with such difficult inferential issues. Therefore, our analysis will attend to questions of 'how?' and 'what for?' in participants' constructions of ME.

\section{Method}

\section{Data and participants}

A total of $56 \mathrm{ME}$ sufferers took part in this study. Data were collected from two sources: face-to-face group (FG) discussions and internet (e-mail) communication with members of ME support groups. The discussion groups, which involved open-ended questions followed by discussion among the participants, were, like focus groups, participant-centred (Puchta and Potter, 2002). Internet data were collected either as part of a nonsynchronous (that is, not 'real time') web-based support group chatline, or via one-to-one e-mails.

Face-to-face group members were recruited by first telephoning contacts for local ME support groups, then writing to their organizing committees and via them to individual members. The letters explained the purpose of 
the study and stated that all data would be made anonymous and treated as confidential. One meeting was held at a researcher's house; the second meeting was held immediately after a support group session in a hospital seminar room. The purpose of the research was discussed with participants, and they were informed that they could withdraw from the study at any time. A total of seven participants were recruited in this way. Each meeting lasted approximately one hour. The data were recorded and transcribed using a modified version of the widely used system developed by Jefferson (summarized by ten Have, 1999).

Internet respondents were recruited through a message posted on a web-based support group, providing the same information as described above. Members of the internet support group received all emails posted to the chatline; therefore their responses to the research questions were available for other members to read and comment on. This is referred to here as 'Internet Chatline Communication' (ICC), and 38 sufferers chose to respond on this basis. However, support group members were asked if they would prefer to communicate on a one-to-one basis so that responses would be private. This communication is referred to here as 'Internet Personal Communication' (IPC), and it involved a further 11 respondents. In the analysis below, the extracts are coded to indicate their source. All of the internet data are quoted with spelling, punctuation and all other features as in the original.

In our efforts to focus on participants' concerns rather than imposing our own, all participants were asked a series of open, general and non-directive questions about their illness, how it affected them and how they dealt with it. This analysis focuses on the responses to questions in which participants were asked to describe ME and its impact on their lives.

\section{Analytic procedure}

Our methods are rooted in the theoretical assumptions that language has a social function and is a medium of social action (Edwards, 1977). Analysis therefore focuses on how it is that descriptions of ME are constructed, and the functions that such constructions might serve. We adopted the variety of discourse analysis developed in the context of discursive psychology and which draws on insights from conversation analysis (see Wooffitt, 2005) because it is best fitted to our aims and the kind of data we had collected.

The term 'discursive psychology' was introduced in 1992 (Edwards and Potter, 1992) and originally indicated an emphasis on construction and the analysis of variability in talk. More recently, discursive psychology has laid a greater emphasis on the analysis of conversations (Edwards, 2000; Potter and Hepburn, 2003). Discursive psychology treats psychology as itself an object in interaction, and views psychology as a part of discourse (Potter, 2005). One key element in discursive psychology is that participants' psychological concerns and categorizations are a topic of study only when they are embedded in interaction. In particular, discursive psychology is 
interested in understanding the way in which speakers construct agency and accountability in what they say.

Discursive psychology developed from a particular interest in naturally occurring, everyday interactions. Our data were gathered for the specific purpose of examining sufferers' descriptions of ME, by means of focus groups and one-to-one interviews. Attempts were made, however, to focus on participants' concerns, for example, by using open and general questions, and thereafter refraining from directing the topic of ongoing discussion. Face-to-face group discussions provide a rich context in which participants respond to each other as well as the interviewer, and many features of everyday conversation are present. E-mail text, however, lacks certain features of oral communication such as pauses, turn-taking and self-repair.

Focus group methodology must be treated carefully within a discursive psychology framework (Edwards and Stokoe, 2004). Kitzinger $(1994,1995)$ has noted that a key advantage of using focus groups to gather data is that participants interact. This allows the turn-by-turn analysis of talk, to see how it is that speakers take up what has just been said, and how their response in turn shapes what might come next. Hutchby and Wooffitt (1998) refer to this as 'next turn proof procedure'. There is far less potential for such analysis in one-to-one interviews, where participants' turns are extended and interaction is minimal. These data can still, however, be examined for conversational devices that have been identified by previous researchers working in the tradition of discursive psychology, and examined for the possible functions they might have. For example, descriptions which are carefully designed to allow inferences to be drawn from them are potentially observable in written as well as verbal communication. Therefore, we treated data extracts as equivalent for the purposes of analysis. So our analysis was driven by an interest in the construction and function of accounts and not by a primary concern to identify differences in types of data (though we will discuss similarities and differences later).

With this in mind, the analytic process was as follows. First, transcripts were read through and inspected closely to identify recurrent patterns or features in the data. Preliminary collections of particular discursive phenomena were then compiled. These seemed to relate to constructions of $\mathrm{ME}$ as serious, enigmatic and not psychological. Next, the analysis of these broadly identified constructions was facilitated by what Edwards (1997) refers to as the 'could-have-been-otherwise' quality of talk. This means that every detail of what is said or written is treated as potentially significant because it was said or written in that particular way and at that particular time. In addition, the analysis was guided by three action-oriented properties of talk: first, to identify the action(s) being accomplished; second to relate the actions identified back to the text to see that participants did indeed orient to the action(s) as described by the analyst; and third, to see how the detail of what was said produced the action(s) in question. In the analysis that follows, we identify and explicate devices that were used to build and warrant various constructions of $\mathrm{ME}$ and the actions accomplished. 


\section{Analysis}

\section{Constructions of $\mathrm{ME}$ as a serious illness}

In the following extract, Billy responds to the question, 'how would you describe having ME to someone who doesn't know anything about it?'. Of course, the local context in which this question is posed is one in which Billy is being invited by the interviewer to provide a description of ME. However, the analytic point of interest here is to examine the way in which Billy produces this description and the social actions to which this description orients.

\section{Extract $1 \quad$ MEICCp58 Billy}

$30[\ldots]$ The alcohol intolerance. (you look to others like you're a

31 chronic alcoholic and you haven't had, or desired, a drink in six

32 months). The IBS [Irritable Bowel Syndrome]. The memory loss.

33 Concentration gone. Can't absorb anything read. Emotional IQ

34 completely zeroed out. Fuzzy vision - it looks as if you're looking at a

35 two-dimensional screen, the 3D effect goes and the focus is difficult.

36 Vertigo or giddiness - things don't look steady. Odd attacks of

37 unaccountable backache or joint pain that may last days, weeks, then

38 just go. Can't get to sleep normally; wake up much too early in the

39 morning, so feel tired as a consequence. Night sweats. Muscles that

40 ache or hurt after minor exercise, like turning the car.

An initial observation is that Billy's description of ME allows the recipient to infer an assessment of the condition rather than stating it directly (as in 'it's awful because ...'). Moreover, his description has several further interesting features. First, it has a list-like quality; that is, instead of describing one or two primary characteristics of his condition (such as extreme tiredness), he describes a number of symptoms and he does so using minimal phrases (for example, 'Concentration gone' rather than 'My concentration is gone'). Second, he uses an analogy ('it looks as if you're looking at a two-dimensional screen') to describe the impact of one symptom ('fuzzy vision'). Third, he produces an example of an effect ('muscles that ache or hurt') and a cause ('turning the car') that are clearly disjunctive. We will explore each of these features in turn.

We noted above that Billy used listing as a device for constructing ME. A similar device can be observed in the following extracts. Moreover, like Billy, respondents in extracts 2 and 3 produce indirect assessments in response to the question.

$$
\begin{array}{ll}
\text { Extract2 } & \text { MEICCp17 Alex } \\
1 & \text { My sleep pattern has gone out of the window. } \\
2 & \\
3 & \text { My muscles ache. } \\
4 & \\
5 & \text { I'm not tired, I'm exhausted yet I haven't moved off the sofa. } \\
6 &
\end{array}
$$


I get 5 or 6 different types of headache.

My vision has deteriorated very quickly.

I start to talk and forget ... in mid sentence.

Oh, I must not forget I suffer from IBS [Irritable Bowel Syndrome].

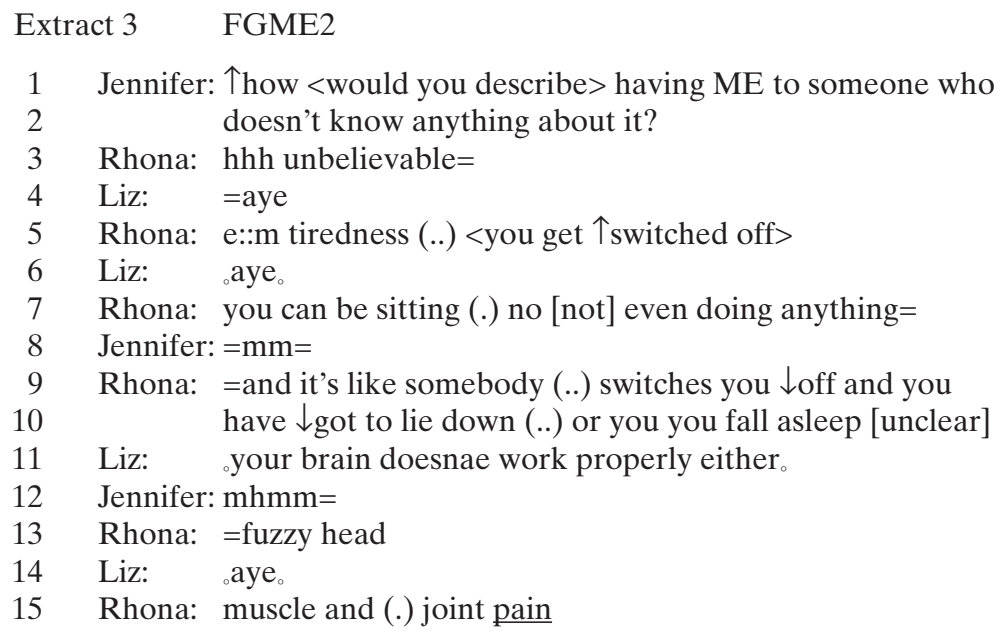

We have already noted how Billy uses minimal phrases and sentences that lack part of a verb or a pronoun to 'do a list'. For example, 'Concentration gone. Can't absorb anything read. Emotional IQ completely zeroed out' (lines 33-34). In extract 2, Alex leaves a blank line between each symptom description, so that his account of ME gives the visual impression of a list. In extract 3, which comes from a face-to-face group rather than internet communication (as extracts 1 and 2), we see how participants collaborate to work up a listing. For example, in lines 5-9, Rhona says 'tiredness (..) you get switched off ...', and Liz follows with 'your brain doesnae work properly either' (line 11). Indeed, by the end of the list, they employ minimal descriptions ('fuzzy head'; 'muscle and joint pain'), which are similar to those we observed in the internet extracts. Moreover, they use them to similar effect, namely making their description hearable as a list.

The lists produced make relevant a range of characteristics: concentration and memory problems, visual problems, IBS, muscular and joint pain, headaches and tiredness. They thereby allow the recipient to infer that the effects of ME are extensive.

A second feature of Billy's (extract 1) description that we noted was his use of analogy. A similar device can be seen in the next three extracts. As was the case with the earlier extracts, the following three responses are produced by participants in reply to a question, 'how would you describe having ME to someone who doesn't know anything about it?'. Once again 
the analytic point of interest here is the way in which sufferers' descriptions are constructed here-and-now, given the potential range of ways that they could have answered the question. In the following three descriptions participants accomplish an answer to the question through analogy, and, as in extracts 1 to 3, they thereby produce an indirect assessment of their condition.

\begin{aligned} & \multicolumn{2}{c}{ Extract 4} \\ & 3 Mandy: \\ & 4 \\ & 5 Claire: \\ & 6 Mandy \\ & 7 Jennifer: \\ & 8 Mandy: \\ & 9 Jennifer: \\ & 10 Mandy: \\ & 11 \\ & 12 Jennifer: \\ & 13 Mandy: \end{aligned}

\section{FGME1}

there $\uparrow$ is a definition that I've read of the (.) ME Action if you i $\mathrm{i}$ mag $\downarrow$ ine (.) that you've got (.) $\downarrow \uparrow$ severe 'flu (.) mhmm you've got a hangover (.)

$\mathrm{mhmm}=$

=so you've got the tummy and the head

yeah $=$

=and all the 'flu aches and pains (.) and then (.) if you imagine you've just run a marathon (.)

mhmm

you $<\uparrow$ put all those together $>$ and you have ME

\section{Extract $5 \quad$ MEICCp1 Lynn}

4 Remember your worst flu virus you had,now run a marathon,on top of 5 that you have a migrain, feel dizzy,hurt from head to toe. Try to play

6 chessblindfolded, and havent slept for a week. Wake up feeling ok,,,15

7 minutes later are unable to even get out of bed with out help,every

8 muscleand joint feels like its on fire, and suddely find out you become

9 dyxlexic, Im sure there are other things ive forgotten.

\section{Extract $6 \quad$ MEICCp1 Emily}

9 I usually tell my friends that I feel like I have been out all night

10 drinking pints of vodka \& tequilla slammers and then forced to run a

11 marathon on top of a dose of flu.

In extracts 4 to 6 , participants respond to the question of what it is like to have ME by producing a set of activities or experiences which we are told are analogous to having ME. There are several interesting features of the way these analogies are constructed. First, they invite the reader or listener to imagine a particular state of affairs: 'if you imagine (.) that you've got (.) severe 'flu'; 'if you imagine you've just run a marathon' (extract 4, lines 4, 10-11). The respondent in extract 5 invites the reader to remember, rather than imagine, 'your worst flu virus you had' (line 4). The things they invite the recipient to imagine include having 'flu, having hangovers, and running marathons. It is therefore implied that these are potentially imaginable states of affairs for the reader or listener.

A second point is that respondents build their descriptions to portray exaggerated or severe cases of these imaginable experiences. So, for example, 
we are invited to imagine 'severe 'flu' (extract 4, line 4), or to remember the 'worst 'flu virus' (extract 5, line 4) and we are invited to imagine running a marathon or climbing Everest, and not exercise that might be assumed to be more commonplace, such as going running, taking exercise or climbing a hill. Similarly, in extract 6 Emily likens her feelings to being out 'all night' and the alcohol intake, the effects of which her friends are invited to imagine, is extreme. She describes drinking a mixture of strong spirits (vodka and tequila) by the pint. Pomerantz (1984) has shown that extreme case formulations, such as 'worst flu virus', or 'all night' can be used to provide the strongest possible case for what is being said, in anticipation of a potentially cynical uptake.

Another way in which participants work up extreme or exaggerated forms of the experiences to which they refer is by juxtaposing them. In extract 4, Mandy has invited the listener to imagine 'you've got (.) severe flu ... you've got a hangover ... you've just run a marathon'. She then says 'you put all those together and you have ME'. In extract 5, the reader is invited to think about having 'flu, 'now run a marathon,on top of that you have a migrain,feel dizzy, hurt from head to toe'. Again, her description makes relevant the concurrence of difficult or unpleasant states of affairs. Emily implies the juxtaposition of having a hangover, and being 'forced to run a marathon on top of a dose of flu'.

So far, we have noted that participants employ analogies in their descriptions of ME. In using these analogies, they appeal to readers' or listeners' experiences, or imaginable states of affairs. At the same time, we have observed the use of several descriptive devices through which respondents portray extreme or exaggerated forms of these imaginable experiences. In this way, respondents are able to invite empathy (by drawing on potentially common experiences) while simultaneously portraying the severity of ME.

A third feature of extract 1 we noted above was the way Billy's description of an effect of ME ('muscles that ache or hurt') was apparently unwarranted by the attributed cause ('turning the car'). A similar descriptive device is employed in the following extracts.

\section{Extract $7 \quad$ MEIPCp2 Dorothy}

24 Holding a pen or a book become thing to be proud of;-)

25 Reading becomes something you can do only in short stints. Walking

26 becomes a trial.

Extract 8 MEICCp13 Lesley

57 standing is one of the most dangerous things one can do.

Extract $9 \quad$ FGME2

816 Rhona: $\quad$ if I $\uparrow$ stand for long $\uparrow$ peri $\uparrow$ ods (.) $<$ I don’t know about you> 
health: 11(1)

$\begin{array}{lll}818 & \text { Liz: } & \text { terrible } \\ 819 & \text { Rhona: } & \text { that } \uparrow \text { kills } \downarrow \text { you } \\ 820 & \text { Liz: } & \text { terrible }\end{array}$

In these extracts, participants describe an activity which they then claim is in some way challenging, for example, 'Holding a pen or a book' and 'reading' (extract 7), 'standing' (extract 8), and 'stand[ing] for long periods' (extract 9). The kinds of activities they describe are mundane, ordinary activities, the sorts of things that everybody might do, and the kinds of activities that are physically relatively undemanding.

They then produce an assessment of that activity. So, holding a pen or book is described as '[a] thing to be proud of' (extract 7), walking is 'a trial' (extract 7) and standing is 'one of the most dangerous things one can do' (extract 8). In extract 9, participants collaborate to produce their assessment of standing as very difficult. In line 818 , Liz evaluates standing for long periods as 'terrible', while Rhona's comment is 'that kills you' (line 819) and Liz affirms that assessment by saying 'terrible' again. These assessments emphasize the exceptional nature (pride in holding a pen) or exceptional difficulty in carrying out the mundane activities made relevant. There is therefore a disjunction between the activity and efforts necessary to achieve it: the difficulty or pride is not merited by the activity described. In other words, participants make an implicit contrast between the difficulties they have, and the kinds of straightforward, physically undemanding tasks that give rise to these difficulties.

A further notable feature of participants' descriptions relates to their use of pronouns. In eight of the ten extracts examined above, participants used the second person plural when describing what it is like to have ME. For example, in extract 3, Rhona states 'you can be sitting [...] and it's like somebody switches you off or you fall asleep' and Liz claims 'your brain doesnae work properly either' (lines 5-11). Similarly, in extract 4 (line 3 onwards) the recipient is invited to imagine 'that you've got (.) severe' flu (.) [...] you've got a hangover' and so on. The use of 'you' rather than the apparently more appropriate pronoun 'I' has the effect of implying generality of symptoms. That is, it is inferred that these symptoms characterize ME in general, they are not specific to the individual describing them. In this way, respondents avoid personalizing their accounts.

A related observation is that in extract 1, Billy omits a pronoun altogether even though he is describing symptoms that are quite specific and so might reasonably be considered to relate to personal experience. He writes '[c]an't get to sleep normally; wake up much too early in the morning, [...] Night sweats.' (lines 38-39). In other places, Billy makes repeated use of the definite article where it would usually be left out -'[t]he alcohol intolerance' (line 30); '[t]he IBS' (line 32); '[t]he memory loss' (line 32). Again, the effect is to suggest that these are symptoms that are generally associated with ME.

There is an interesting exception to this pattern. In extract 9 above, Rhona uses the first person singular pronoun. She says 'if I stand for long periods' (lines 816-819). But there follows a short pause, and an insertion clause in 
which she explicitly seeks some sort of collaboration regarding the effects of standing - 'I don't know about you'. Liz takes this up as an invitation to provide an assessment, but does so selectively, in that she does not refer to her own experience. Instead, she uses no pronoun at all: 'terrible'. Similarly, in Rhona's turn that follows, her claim is general rather than personal: 'that kills you'. In this case then, initial first person is changed and participants use the pronoun 'you' to suggest general features of ME and to avoid suggesting an individual, or psychological, basis for ME.

\section{Constructions of $\mathrm{ME}$ as an enigmatic illness}

There is a further feature of the extracts above that we wish to examine; in particular, the ways respondents build up the condition as puzzling in one or both of two ways. One is through the use of terms such as 'odd', and the other is through the use of contrasting states of affairs.

\section{Extract $10 \quad$ MEICCp26 George}

3 You feel profoundly tired physically and mentally for no good reason.

4 You get odd aches and pains

Extract 11 (also 5) MEICCp1 Lynn (for ease of reference, the original extract number appears in brackets)

6 Wake up feeling ok,,,,15

7 minutes later are unable to even get out of bed with out help

Extract 12 (also 2) MEICCp17 Alex

5 I'm not tired, I'm exhausted yet I haven't moved off the sofa.

Extract 13 (also 1) MEICCp58 Billy

36 Vertigo or giddiness - things don't look steady. Odd attacks of

37 unaccountable backache or joint pain that may last days, weeks, then

38 just go.

\section{Extract 14 (also 3) FGME2}

7 Rhona: you can be sitting (.) no [not] even doing anything=

8 Jennifer: $\mathrm{mm}=$

9 Rhona: =and it's like somebody (..) switches you $\downarrow$ off and you

10 have $\downarrow$ got to lie down (..) or you you fall asleep [unclear]

11 Liz: your brain doesnae work properly either.

29 Liz: $\quad$ em (..) it's just a weird weird thing <it's no $>$ [not] one thing

30 and <it's no [not] one thing $>$ (..) two days in a row

In extract 10, George writes that '[y] ou get odd aches and pains' (line 4; emphasis added) and in extract 13, Billy writes about ' $[o] d d$ attacks of unaccountable 
backache or joint pain' (lines 36-38; emphasis added). In extract 14, Liz makes the claim 'em (.) it's just a weird weird thing' (Line 29; emphasis added). In this way, they are able to introduce unpleasant symptoms and simultaneously suggest that they are inexplicable; in other words, it is implied that they do not have a specifiable precursor. Liz reinforces her characterization of ME as 'weird' by implying that its symptoms are unpredictable from day to day ('it's no one thing and it's no one thing (..) two days in a row' (lines 29-30).

A second observation concerns the use of contrasts. For example, Lynn uses the following contrast formulation: '[w]ake up feeling ok,,,[sic]15 minutes later are unable to even get out of bed with out help' (extract 11, lines 6-7). In extract 12, Alex writes 'I'm not tired, I'm exhausted yet I haven't moved off the sofa' (line 5). Similarly, in extract 14, Rhona contrasts 'sitting (.) no even doing anything [...]' with 'it's like somebody (..) switches you off and you have got to lie down' (lines 7-10). In each case, one state of affairs (feeling $\mathrm{OK}$, being on the sofa, sitting not doing anything) is contrasted with another state of affairs characterized as debilitating (being unable to get out of bed on one's own, feeling exhausted, having to lie down). These descriptions are designed to allow the recipient to draw certain inferences; in particular these are not accidental conjunctions. Instead, there is portrayed an unexpected relation between the two states of affairs. That is, Lynn conjoins 'wake up feeling ok' with her state ' 15 minutes later'; Alex signals the contrast between his previous state of inactivity and the exhaustion that he reports with the term 'yet'. Rhona characterizes the change from 'doing nothing' to 'having to lie down' as abrupt through the use of the simile 'somebody switches you off'.

These descriptive devices portray the symptoms attributed to ME as puzzling and imply that there is no rational basis for the problems sufferers claim to experience. This is made more explicit in George's description, 'you feel profoundly tired physically and mentally for no good reason' (emphasis added) and in Billy's characterization of backache as 'unaccountable' and something that after days or weeks 'then just go[es]' (which draws attention to the lack of imputed reason for their disappearance). In addition, by constructing the basis of symptoms as irrational, participants are also able to make available the inference that it is not something they have done that has led to the debilitating effects they describe. This can be inferred from the nature of activities to which they refer (not moving off the sofa or not even doing anything) and in Rhona's characterization of somebody switching her off. Through passive inactivity and attributing switching off to external agency, participants imply that they are not personally accountable for their fatigue.

\section{Constructions of ME as 'not psychological'}

In the following extracts, participants produce and deny claims about what ME is not. In extracts 15 and 16, respondents claim that ME is not depression, and in 17 that it is not laziness. These extracts occurred at various points in the transcripts and were not generated in immediate response to a particular question. 


\section{Extract $15 \quad$ FGME2}

475 Liz: a:nd I mean before I $\uparrow$ went to the doctor (.) the last

476

477

478

479

480

481

482

483

$484 \quad$ Liz time before I was ( ) diagnosed or ( ) < she agreed with me> ( ) I did say to <my husband > 'look (..) do 个you think it's depression or do you think there's something wrong with me ( ) do you think (.) I'm <just making it $>$ all $\uparrow$ up or whatever' he says <'no' he says $>$ 'I live with you day to day and (.) and $\uparrow \underline{I}$ know there is definitely something (.) $\downarrow$ wrong'

Jennifer: $\mathrm{mm}=$ $=<$ it's no [not] depression $>$ I actually (.) suffered from depression

(.) years ago (.) a:nd so I knew it wasnae [wasn't] depression

\section{Extract 16 MEIPCp7 Dorothy}

29 I called my husbaband into the Drs surgery and told him in front of the

30 Dr what his dx [diagnosis] was. My husband laughed and said that

31 there was no way I was depressed and that as his field of work was

32 mental health he reckoned that he might have spotted the signs in his

33 wife were they present.

\begin{tabular}{|c|c|c|}
\hline \multicolumn{2}{|c|}{ Extract 17} & FGME2 \\
\hline \multicolumn{3}{|l|}{680} \\
\hline 681 & Jennifer: & $: \mathrm{mm}=$ \\
\hline 682 & Liz: & nothing right about me and (.) I couldnae [couldn't] \\
\hline 683 & & understand this wanting to sleep all the time (.) I've never \\
\hline 684 & & been late going to bed (..) but to go to bed during the day or fall \\
\hline 685 & & asleep in a $\uparrow$ chair \\
\hline 686 & Jennifer: & {$[\mathrm{mmhmm}$} \\
\hline 687 & Rhona: & $\mathrm{mhmm}]$ \\
\hline 688 & Liz: & $\downarrow$ never (..) never (.) ehm (....) and no [not] to 。'oh I cannae \\
\hline $\begin{array}{l}689 \\
690\end{array}$ & Liz: & $\begin{array}{l}\text { be bothered'。 when you } \uparrow \text { say 'cannae be } \uparrow \text { both } \uparrow \text { ered' (.) it } \\
\text { sounds as if }(.)<\text { to me }>\text { lazy }\end{array}$ \\
\hline 691 & Rhona: & aye \\
\hline 692 & Jennifer: & : mhmm \\
\hline 693 & Rhona: & yeah \\
\hline 694 & Liz: & $<$ it it's> (..) you know it's 个no [not] lazy it's (..) you just ( ) \\
\hline 695 & & 个havenae got the energy to $\uparrow$ do it.h (.) and that's what you \\
\hline 696 & & say <'oh I cannae [can't] be bothered doing that'> but it (.) \\
\hline 697 & & it's $\uparrow$ no [not] that it's (.) you haven't got the energy to get \\
\hline 698 & & yourself $\uparrow$ up out the chair (.) to $\uparrow$ do $\downarrow_{\text {it }}($.$) and (..) you just$ \\
\hline 699 & & cannae [can't] fathom out what what's going $\uparrow$ on \\
\hline
\end{tabular}

In the first part of these extracts, participants make relevant a potential diagnosis. Dorothy (extract 16) states indirectly that her condition may be seen as depression by giving an account of her husband's receipt of the 
doctor's diagnosis (line 31). By contrast Liz (extract 15) introduces this description of her condition directly via reported speech ('I did say to my husband "look (..) do you think it's depression ..."'). Liz describes one circumstance under which you might say 'I cannae be bothered' and states that this might be ascribed to laziness ('it sounds as if (.) to me lazy').

However, each participant then denies the potential diagnosis she has just produced. Liz produces the counterclaims 'it's no depression' (line 484) and (line 694) 'it's no lazy', while Dorothy quotes her husband who, she claims, said 'there was no way I was depressed' (line 31). Indeed, her account of his denial is preceded by the claim ' $[\mathrm{m}] \mathrm{y}$ husband laughed'. Laughter is a surprising reaction to a being told of a partner's depression, and this description implies that such a diagnosis is not only wrong but risible.

These denials employ a number of devices to build the factual status of the counterclaim. For example, Liz and Dorothy make relevant their husbands as witness to their condition. Potter (1996) notes the usefulness of providing corroboration in rendering an account factual. Moreover, that they introduce 'husband' as corroborating their account further strengthens their claims. That is, Whalen and Zimmerman (1990) among others have noted that category entitlement can be used to warrant claims to knowledge, and in this case, someone in the category of a husband, could be assumed to have detailed knowledge of his wife's mental state. Indeed, Liz makes explicitly relevant her husband's close relationship with her: 'I live with you day to day (.) and I know there is definitely something wrong' (lines 480-82). Dorothy refers three times to their relationship as a married couple, referring to 'husband' twice and 'the signs in his wife' (lines 32-33; emphasis added). Dorothy's account is particularly effective: she produces a second relevant category description of her husband, writing that 'his field of work was mental health'. The categorical claims are designed to make available certain inferences, which are made explicit here: 'he reckoned that he might have spotted the signs in his wife were they present'. Thus, the husband's credentials as a person with knowledge of depression, and as someone who has a close relationship with Dorothy, are used to expose the doctor's diagnosis of depression as inaccurate.

It is worth noting that these statements about the respondent's condition are portrayed as husbands' observations. That is, Liz's account in extract 15 is produced in such a way that her question ('I did say to my husband "look (..) do you think it's depression or ..."') and his counterclaim ('no ... I live with you ... and I know there is definitely something (.) wrong') can be heard as reported speech (lines 477-79). Dorothy, in extract 17, uses indirect reported speech in lines 30-31 where she writes: ' $[\mathrm{m}] \mathrm{y}$ husband laughed and said that there was no way I was depressed'. In all these cases, participants are using 'active voicing'. Wooffitt (1992) has shown that active voicing is used to construct the reality of the reported speech. Thus, when Liz quotes her husband, the account appears more convincing than if she had merely summarized what he had said in her own words. 
In extract 17, Liz uses a further device, specifically an appearance/reality formulation, to construct her incapacity as being due to lack of energy rather than laziness. Potter and Wetherell (1989) have shown how this formulation can help to construct the reality of what is being claimed. It involves setting up a version as the one that may appear to be obvious, then undermining it by producing the version that is 'real'. Here, Liz makes the following contrast: she says 'when you say "cannae be bothered" (.) it sounds as if (.) to me lazy [...] it it's (..) you know it's no lazy it's (..) you just havenae got the energy to do it' (lines 689-95). The appearance of ME is constructed as one in which the sufferer lacks the motivation to do something. With 'it sounds as if', Liz orients to the interpretation that others might have of ME sufferers' inactivity. Immediately after this, there is what seems to be a repair. That is, we might expect in the context something like 'it sounds as if you're being lazy'. What Liz does is to pause briefly then say 'to me lazy'. She therefore actively positions herself as a person who understands this assumption of a lack of motivation. This works to construct Liz herself as impartial, making the same initial assumptions that any other observer might have done. In turn, this construction helps to strengthen the reality claim that follows.

\section{Discussion}

We mentioned earlier that previous discursive research focused on the ways that sufferers deal with particular problematic assumptions about ME, including the ways that it is regarded as a psychological rather than a physical condition and that it is therefore somehow 'not real': it is just tiredness, laziness or, as one study found, 'masked depression' (Horton-Salway, 2004). Our work complements and extends these findings by showing how various constructions of $\mathrm{ME}$ are designed to address further possibly damaging implications for the sufferer of claiming to have ME/CFS.

In the first section of the analysis, we identified several descriptive devices, which, we argued, worked to build the seriousness of ME in various ways. These included, first, listing, which was used to portray ME as an accumulation of symptoms, and to claim an extensive range of problems. Second, vivid analogy with everyday experiences that cause debilitating tiredness (for example, having the 'flu or running a marathon) was used to imply the severe impact of the illness. Third, by comparing ME symptoms to extreme forms of more everyday experiences, participants orient to the potential charge that their fatigue is similar to the kinds of tiredness commonly felt by other people, and is therefore not a serious condition. Their invitation to recipients to imagine these experiences functioned to evoke empathy. Fourth, participants produced an implicit contrast between mundane activities and the assessment of difficulty in doing them, which further constructed their physical condition as serious. These descriptions enabled sufferers to deflect the potential charge that their illness was 
brought on by their previous levels of activity. This in turn can be seen as an orientation to the possible interpretation of ME as an illness of 'high achievers', brought on by an unusually active and demanding lifestyle (see also Horton-Salway, 2001, who makes a similar observation).

Finally, we observed a preference for the second person plural and noted that its use helps to avoid personalizing sufferers' experiences, because it allows the recipient to infer that what is said is generally applicable. Bülow and Hydén (2003:238) also showed that personal experiences were avoided, in part due to 'a general assumption that personal stories about suffering do not belong in medical discourse'. Indeed, Åsbring and Närvänen (2003) showed that physicians in their study regarded symptoms as not serious (they can be lived with), they sometimes questioned patients' morality (especially their work ethic), and categorized them as ambitious, active, illness-fixated and so on. The orientation of sufferers to the issues we have identified is therefore not surprising.

In the second section, we showed how participants used several linguistic devices (descriptive terms and contrast) to portray their illness as enigmatic and to imply the non-rational and unpredictable status of their symptoms. This allowed them to emphasize their passive role in developing symptoms, and implied that they were not responsible for developing ME/CFS. So, whereas Tucker (2004) showed how issues of responsibility and blame were dealt with through constructions of ME as an organic illness, our analysis reveals a further way of dealing with issues of accountability.

In the third section, we showed how participants' accounts were designed to warrant what ME/CFS is not. Corroboration, category entitlements, appearance/reality formulations (Potter and Wetherell, 1989) and active voicing (Wooffitt, 1992) of 'reliable witness' testimony were used to build the factual status of their claims that ME/CFS is not laziness, nor is it depression. By making relevant and then denying these meanings of $\mathrm{ME} /$ CFS, participants were better able to orient to and then reject explicitly the kinds of assumptions that are made about the illness. Horton-Salway (2001) and Tucker (2004) note sufferers' use of similar devices (corroboration and active voicing) to claim their illness is physical, and reject its assumed status as psychological.

Our concern in this paper was not to categorize the nature of respondents' beliefs regarding the causes or explanations for having ME, but simply to analyse accounts of the experience of having ME. In particular, our analysis focused on the functions accomplished through the details of the descriptions produced by participants. We showed how their accounts were designed to address negative or otherwise problematic inferences that may be made about them. This is important because the rhetorical and interactive nature of illness accounts has been ignored in cognitive behavioural (Horton-Salway, 2001) and other approaches to treatment. ME sufferers' descriptions of their illness have been taken at face value as evidence for theoretical interpretations of the cause of this condition or, according to 
Horton-Salway (2001), as evidence of their attributions or personality. Thus, sufferers' apparent preoccupation with its seriousness, or its enigmatic nature, has been used to support the use of CBT to change 'dysfunctional' beliefs (Wessely, 1996). Sufferers' accounts might, however, stress the seriousness and mysterious nature of ME to counter claims that it is not a legitimate, physical illness. In other words, the kinds of assumptions built into common treatments for ME/CFS are just those that participants reject. Thus, it is not enough to treat sufferers' descriptions as 'mere reflections' of experience. They must be understood in the context of the inferential and interactional issues they are designed to address. It is therefore important to understand patients' versions, and how they are built, because effective treatment requires the doctor to work with patients' descriptions of their experiences rather than imposing their own (cf. Clements et al., 1997).

Our findings are therefore in line with, but extend, those of previous studies. This is significant because, as explained above, one of our primary aims was to compare data from different sources in order to assess the utility of the internet as a research tool. So, in this study, data were collected from two sources: face-to-face group discussions among members of a support group and questions answered via an internet chatroom and personal e-mails. In the analysis, we made no prior distinction between data from different sources. Instead, we let any similarities and differences emerge through our subsequent inspection of our analytic findings. Let us now, then, assess the use of these different methods.

We have observed that the devices and interactional concerns identified were manifest in both internet and face-to-face group data. For example, we found the use of listing, vivid description and analogy, and reference to a 'reliable witness' in both types of data. Of course, there were some minor differences in the details of production due to the different media. In the face-to-face group, listing was accomplished collaboratively within sequences of turns. By contrast, in the internet data, line breaks and grammatical omissions were used to create lists. There was also an absence of pauses, hesitancy markers and so on in the written communication.

Moreover, the themes that emerged were similar, suggesting that participants were attending to the same kinds of interactional concerns. In one sense, this is perhaps not surprising. Most of the e-mail correspondence was done via a chatline in which correspondents' responses were simultaneously emailed to other members of the group and even the personal e-mails were addressed to another person (the first author). Therefore, all the data were provided in a context of some level of social interaction, and the fact that we have observed participants addressing the inferential implications of their accounts indicates that they were sensitive to this context.

The internet is therefore a fruitful means of collecting data which has further practical advantages for research with people who suffer debilitating fatigue, among other problems. Moreover, by using computer-aided communication, access could be available to people over a wide geographic 
area, some of whom may be housebound and might not otherwise have been able to participate in research (or in support groups).

Previous studies have not attended to the internet as a domain for interactions and support among sufferers. This study goes some way to remedying this omission. This is important because sufferers often experience reduced opportunities for everyday social interactions. In extreme cases, the severity of the problem may even mean that sufferers are denied the opportunity to attend face-to-face peer group support meetings or to engage fully with therapeutic services. In this sense, sufferers are faced with problems of social exclusion from the very groups and services which in principle could provide them with support.

\section{References}

Antaki, C., Ardévol, E., Núñez, F. and Vayreda, A. (2005). 'For she who knows who she is': Managing accountability in online forum messages. Journal of ComputerMediated Communication, 11(1), 1-18.

Åsbring, P. and Närvänen, A.-L. (2003). Ideal versus reality: Physicians' perspectives on patients with chronic fatigue syndrome (CFS) and fibromyaligia. Social Science and Medicine, 57, 711-20.

Banks, J. and Prior, L. (2001). Doing things with illness: The micro-politics of the CFS clinic. Social Science and Medicine, 52, 1-23.

Bowker, N. and Tuffin, K. (2004). Using online medium for discursive research about people with disabilities. Social Science Computer Review, 22(2), 228-241.

Bülow, P.H. (2004). Sharing experiences of contested illness by storytelling. Discourse and Society, 15(1), 33-53.

Bülow, P.H. and Hydén, L.-C. (2003). Patient school as a way of creating meaning in a contested illness: The case of CFS. health: An Interdisciplinary Journal for the Social Study of Health, Illness and Medicine, 7(2), 227-49.

Campion, P. (1998). Report on NHS services for people with chronic fatigue syndrome/myalgic encephalomyelitis. The National Task Force on CFS/ME.

Clarke, J.N. and James, S. (2003). The radicalized self: The impact on the self of the contested nature of the diagnosis of chronic fatigue syndrome. Social Science and Medicine, 57, 1387-95.

Clements, A., Sharpe, M., Simkin, S., Borrill, J. and Hawton, K. (1997). Chronic fatigue syndrome: A qualitative investigation of patients' beliefs about the illness. Journal of Psychosomatic Research, 42, 615-24.

Cooper, L. (1997). Myalgic encphalomyelitis and the medical encounter. Sociology of Health and Illness, 19(2), 186-207.

Edwards, D. (1997). Discourse and cognition. London: Sage.

Edwards, D. (2000). Extreme case formulations: Softeners, investment and doing nonliteral. Research on Language and Social Interaction, 33, 347-73.

Edwards, D. and Potter, J. (1992). Discursive psychology. London: Sage.

Edwards, D. and Stokoe, E. (2004). Discursive psychology, focus group interviews and participants' categories. British Journal of Developmental Psychology, 22, 499-507.

Fernback, J. (2003). Legends on the net: An examination of computer-mediated communications as a locus of oral culture. New Media \& Society, 5(1), 29-45. 
Fukuda, K., Straus, S.E., Hickie, I., Sharpe, M.C., Dobbins, J.G. and Komaroff, A. (1994). The chronic fatigue syndrome: A comprehensive approach to its definition and study. Annals of Internal Medicine, 121(12), 953-9.

Hardy, M. (1999). Doctor in the house: The internet as a source of lay health knowledge and the challenge of expertise. Sociology of Health and Illness, 21(6), 820-35.

Holmes, G.P., Kaplan, J.E., Gantz, N.M., Komaroff, A.L., Schonberger, L.B. et al. (1988). Chronic fatigue syndrome: A working case definition. Annals of Internal Medicine, 108, 387-9.

Horton (1996). Frustrating survey of chronic fatigue. Lancet, 348(9033), 971.

Horton-Salway, M. (2001). Narrative identities and the management of personal accountability in talk about ME: A discursive psychology approach to illness narrative, Journal of Health Psychology, 6(2), 247-59.

Horton-Salway, M. (2002). Bio-psycho-social reasoning in GPs' case narratives: The discursive construction of ME patients' identities. health: An Interdisciplinary Journal for the Social Study of Health, Illness and Medicine, 6(4), 401-421.

Hutchby, I. (2001a). Conversation and technology: From the telephone to the internet. Cambridge: Polity.

Hutchby, I. (2001b). Technologies, texts and affordances. Sociology, 35(2), 441-56.

Hutchby, I. and Wooffitt, R. (1998). Conversation analysis: Principles, practices and applications. Cambridge: Polity.

Kitzinger, J. (1994). The methodology of focus groups: The importance of interaction between research participants. Sociology of Health \& Illness, 16(1), 103-121.

Kitzinger, J. (1995), Qualitative research: Introducing focus groups. British Medical Journal, 311(7000), 299-302.

Lamerichs, J. and te Molder, H. (2003). Computer-mediated communication: From a cognitive to a discursive model. New Media \& Society, 5(4), 451-73.

Levine, P.H. (1997). Epidemiologic advances in chronic fatigue syndrome. Journal of Psychiatric Research, 31(1), 7-18.

Nettleton, S. and Burrows, R. (2003). E-scaped medicine? Information, reflexivity and health. Critical Social Policy, 23(2), 165-85.

Pomerantz, A. (1984). Extreme case formulations: A way of legitimising claims. Human Studies, 9, 219-30.

Potter, J. (1996). Representing reality: Discourse, rhetoric and social construction. London: Sage.

Potter, J. (2005). Making psychology relevant. Discourse \& Society, 16, 739-47.

Potter, J. and Hepburn, A. (2003). 'I'm a bit concerned': Early actions and psychological constructions in a child protection helpline. Research on Language and Social Interaction, 36, 197-240.

Potter, J. and Wetherell, M. (1989). Fragmented ideologies: Accounts of educational failure and positive discrimination, Text, 9(2), 175-90.

Puchta, C. and Potter, J. (2002). Manufacturing individual opinions: Market research, focus groups and the discursive psychology of evaluation. British Journal of Social Psychology, 41(3), 345-63.

Royal College of Physicians (1996). Chronic fatigue syndrome: Report of a joint working group of the Royal Colleges of Physicians, Psychiatrists and General Practitioners. London: Royal College of Physicians, CR54.

Rutter, D.R. (1984). Looking and seeing: The role of visual communication in social interaction. London: Wiley. 
Schluederberg, A., Straus, S.E., Peterson, P., Blumenthal, S., Komaroff, A.L., Spring, S.B., Landay, A. and Buchwald, D. (1992). Chronic fatigue syndrome research: Definition and medical outcome assessment, Annals of Internal Medicine, 117(4), 325-31.

Sharpe, M.C., Archard, L.C., Banatvala, J.E., Borysiewicz, L.K., Clare, E.W., David, A., Edwards, R.H., Hawton, K.E., Lambert, R.J. and Lane, R.J. (1991). A Report-Chronic Fatigue Syndrome - Guidelines for Research. Journal of the Royal Society of Medicine, 84(2), 118-21.

Short, J., Williams, E. and Christie, B. (1976). The social psychology of telecommunications. London: Wiley.

ten Have, P. (1999). Doing conversation analysis: A practical guide. London: Sage.

Tucker, I. (2004). 'Stories' of chronic fatigue syndrome: An exploratory discursive psychological analysis. Qualitative Research in Psychology, 1, 153-67.

Wessely, S. (1996). Cognitive-behaviour therapy for patients with chronic fatigue syndrome: Why? In M.A. Demitrack and S.E. Abbey (Eds.), Chronic fatigue syndrome: An integrative approach to evaluation and treatment. New York: Guilford Press.

Wessely, S., Hotopf, M., and Sharpe, M. (1998). Chronic fatigue and its syndromes. Oxford: Oxford University Press.

Whalen, M.R. and Zimmerman, D.H. (1990). Describing trouble: Practical epistemology in citizen calls to the police. Language in Society, 19, 465-92.

Wooffitt, R. (1992). Telling tales of the unexpected: The organisation of factual discourse. Hemel Hempstead: Harvester Wheatsheaf.

Wooffitt, R. (2005). Conversation analysis and discourse analysis: A comparative and critical introduction. London: Sage.

Yates, S.J. (2001). Researching internet interaction: Sociolinguists and corpus analysis. In M. Wetherall, S. Taylor and S.J. Yates (Eds.) Discourse as data: A guide for analysis. London: Sage.

\section{Author biographies}

JENNIFER GUISE works as a Lecturer in Health Studies at the University of Abertay, Dundee. Her research interests involve aspects of different chronic illnesses, and in particular the ways in which chronic illness, and its treatment, can affect the sufferer's identity and relationships with others. She is also currently involved in developing a multi-disciplinary dependency tool aimed at improving patients' experience and efficiency of health services, and in researching psychological wellbeing in offshore oil workers.

SUE WID D I C о в в is a lecturer in Psychology at the University of Edinburgh, UK. She is interested in conversation and discourse analysis, in their utility in exploring matters of identity and applying conversation analysis (e.g. to therapy). She is also interested in personal and social identity, and cultural variations in self conception and individuality.

ANDY MCKINLAY is a senior lecturer in social psychology at the University of Edinburgh, UK. He is interested in social identity and the ways in which categorizations of self and others are produced as social accomplishments in talk. He is also interested in some of the broader concerns of conversation analysis and discursive psychology. 